\title{
Ar-quiteturas. Os infláveis como estratégia de reinterpretação do lugar
}

\author{
Adriana Sansão Fontes \\ LabIT-PROURB-FAU/UFRJ (Laboratório de Intervenções Temporárias e Urbanismo Tático). \\ Universidade Federal do Rio de Janeiro \\ Contato: adrianasansao@gmail.com
}

\section{Fernando Espósito}

LObE Hab - PPGarq - DAU/PUC-Rio (Laboratório de Observação do Espaço Habitado).

Pontifícia Universidade Católica do Rio de Janeiro

Contato: fernando.esposito@puc-rio.br

\author{
Sergi Arbusà \\ Doutorando PROURB-FAU/UFRJ. \\ Universidade Federal do Rio de Janeiro \\ Contato: sergiarbusa@gmail.com
}

\section{RESUMO}

A arquitetura, disciplina chamada a projetar os lugares da vida, opera normalmente dentro de uma lógica que tem como principal objetivo abrigar os atos humanos. Sua condição de objeto edificado exige uma resposta adequada não só material, estrutrural, espacial e ambiental, mas também no atendimento das exigências mais vitais desses atos. A arte, por outro lado, pode responder com uma liberdade quase absoluta, descomprometida com os hábitos próprios do viver, em que o ato de habitar pode ser questionado, liberando-se das responsabilidades com a vida. Este trabalho apresenta um recorte da obra do coletivo artisitico Penique Productios - os infláveis - suas referências e metodologia, destacando duas intervençôes no Rio de Janeiro, realizadas em uma parceria entre Penique, o DAU PUC-Rio e a FAU UFRJ. O denominador comum é estabelecer uma conexão entre arquitetura, cidade e arte, por meio de obras coletivas de grande porte, efêmeras e habitáveis, que dialogam com o lugar existente, estimulando sua reintepretação.

Palavras-chave: Infláveis, intervenções efêmeras, intervenções site-specific, arte contemporânea

\section{ABSTRACT}

Architecture, a discipline called to design the living places, usually operates within a logic that has as main objective welcoming human acts. Its status as a built object requires an adequate response not only material, structural, spatial and environmental, but also in meeting the most vital demands of these acts. Art, on the other hand, can respond with almost absolute freedom, uncompromising with the proper habits of living, in which the act of dwelling can be questioned, freeing itself from its responsibilities related to life. This paper presents a clipping of the work of the artistic collective Penique Productios - the inflatables - their references and 
methodology, highlighting two interventions in Rio de Janeiro, carried out in a partnership between Penique, DAU PUC-Rio and FAU/UFRJ. The common denominator is to establish a connection between architecture, city and art, through large, ephemeral and habitable collective works that dialogue with the existing place, stimulating its reinterpretation.

Key-Words: Inflatables, ephemeral interventions, site-specific interventions, contemporary art

\section{Re-habitar pela arte}

Arquitetura e arte. Duas disciplinas com distintos propósitos mas com aproximados processos e métodos de criação, que permitem estabelecer relaçóes generosas e frutíferas mútuas. Entretanto, não podemos negar as importantes diferenças que as definem. A distância metodológica entre elas pode ser muito tênue, quase imperceptível, mas são evidentes as claras diferenças quando operamos dentro do campo disciplinar para o qual cada uma delas é chamada. A arquitetura, destinada a projetar os lugares da vida, opera dentro dos limites da racionalidade ou lógica do viver, do abrigar os atos humanos, uns mais mundanos, outros mais sublimes. Ainda, sua condiçáo de objeto construído exige da arquitetura uma resposta material, estrutural e ambiental, necessária para atender a essas exigências. Essas lógicas podem mudar em cada época, entrar em crise, sofrer deslocamentos, ajustes e desajustes, mas sempre em resposta aos processos do construir e aos hábitos do viver. A arte, por outro lado, pode responder com uma liberdade quase absoluta, descomprometida com essa mundanidade e com os hábitos próprios do viver, do sobreviver, em que o ato de habitar pode ser questionado, desconstruído ou abandonado, liberando-se das responsabilidades com a vida. No entanto, como já reconhecia Kandinsky (1972), a obra de arte não é um fenômeno casual que permanece indiferente no mundo espiritual. Ela possui, como todo ente, forças ativas e criativas. A obra de arte vive e atua, colabora na criação da atmosfera espiritual. Segundo ele, o artista não só pode, mas deve utilizar as formas e recursos de forma livre para seus fins. Para Kandinsky, essa "liberdade total deve estar baseada no fundo da necessidade interior chamada honradez. Este princípio não só serve para a arte, mas também para a vida mesma” (Kandinsky, 1972, p. 114).

Este princípio de conexão entre a arte como ação liberada e liberadora do mundano e a arte como interferência na vida define um vínculo entre arte e arquitetura. Como afirmado por Thibaud (2012), a cidade contemporânea está passando por mudanças que estão redesenhando sua aparência, criando novos contextos de sensibilidade. Nesses contextos, o corpo e os sentidos ganham valor como campo de investigação e experimentação por meio do que Thibaud chama uma "estética das ambiências", que permite retornar a uma teoria fenomenológica da percepção sensível, desafiando a divisão tradicional entre sujeito e objeto. Para Thibaud, a "estética das ambiên- 
cias" é o que questiona essa divisão, oferecendo uma alternativa a essa forma de pensamento, mostrando como a ambiência tanto precede quanto é indissociável das propriedades materiais do meio ambiente e dos estados afetivos do sujeito sensível.

A noção de ambiência restitui o lugar dos sentidos na experiência dos espaços vividos; ela permite caracterizar nossas formas de experienciar a vida urbana; ela auxilia também a imaginar e criar espaços urbanos e arquitetônicos. A ambiência não existe somente no nível de recepção sensorial, mas também no nível de produção material (Thibaud, 2012, p. 10).

Por outro lado, Bajtin (1997) afirma que na cultura humana a arte e a vida são capazes de se relacionar, sendo o vínculo entre elas quase sempre algo mecânico e externo. O ser humano se afasta das turbaçóes da vida e se aproxima do campo de criação, do mundo da inspiração, da arte, que é atrevida e auto suficiente, porque não precisa se responsabilizar pela vida (Bajtin, 1997, p. 11).

Bajtin observa essa separação entre a vida e a arte como algo normal e necessário, como um natural deslocamento entre a existência e a experiência criativa, entre o sujeito que está na arte e aquele que está na vida, mas também observa que existe uma forma de garantir o nexo interno entre os elementos de uma personalidade (por uma parte sujeito autor e por outra o sujeito vivente), que se dispóe a uma articulação das variáveis de um determinado contexto. Essa garantia é a unidade responsável nessa personalidade.

Para Bajtin, tanto a arte como a vida têm facilitada sua tarefa quando se desfazem da responsabilida- de, porque é mais fácil criar sem se responsabilizar pela vida, e porque é mais fácil viver sem levar em conta a arte. $\mathrm{A}$ arte e a vida certamente não são o mesmo, explica Bajtin, porém, devem e podem estar unidas dentro da personalidade responsável do sujeito. Desde a perspectiva de Merleau-Ponty (apud. Pallasmaa, 2006), isso significa fazer do corpo humano o centro do mundo da experiência. É por meio de nossos corpos que escolhemos nosso mundo e que nosso mundo nos escolhe.

Nossos corpos e movimentos estão em interação constante com o entorno: o mundo e o eu se informam e se redefinem constantemente um ao outro. $\mathrm{O}$ preceito de corpo e a imagem do mundo passam a ser uma única experiência existencial contínua: não existe o corpo separado do seu domicílio no espaço, e não há espaço que não esteja relacionado com a imagem inconsciente do eu perceptivo (Merleau-Ponty apud. Pallasmaa; 2006, p. 42).

Assim, habitar faz referência a uma relação poética e fenomenológica com o mundo, explica Norberg-Schulz (2005), insistindo na necessidade de uma atitude de devoção para penetrar no significado das coisas. Se essa atitude é ensinada, ela pode ser a base e "fundamentação natural para que o ser humano entenda seu estar no mundo". Portanto, a fenomenologia, no sentido da consciência do entorno, deveria se converter no centro cumulativo de uma educação mais sensível ao mundo (Norberg-Schulz, 2005, p. 250).

As experiências que aqui se apresentam, desenvolvidas pelo coletivo Penique Productions e seus colaboradores, são, por um lado, obra artística e, por outro, interferências no espaço cotidiano, alteraçôes 
no habitar, operando sobre lugares comuns e espaços coletivos, reinterpretados por meio de açóes de caráter efêmero que permitem uma conexão entre arte e vida.

\section{A obra do coletivo artístico Penique Productions}

Penique Productions é um coletivo artístico que nasceu na faculdade de Belas Artes da Universitat de Barcelona, em 2007, com uma primeira proposta de intervenção inflável, intitulada Espai 1. Serendipity ${ }^{1}$ seria uma boa palavra para descrever o decorrer do processo criativo que desencadeou essa primeira instalação. A vontade não era a de fazer uma intervenção imersiva, no sentido de que o público pudesse acessar o inflável e "consumir" a sensação de uma arquitetura reinterpretada através da instalação, mas sim uma escultura invasiva que ocupasse toda a sala, não permitisse a entrada do público, e a obra só pudesse ser apreciada pelas portas e janelas da sala. A ideia funcionou, porém, quando o inflável estava pronto, revelou-se acessível, assumindo-se o acaso e, dessa forma, iniciando-se o projeto Penique Productions.

A partir desse momento, o projeto foi evoluindo à procura de novos desafios em relaçáo à escolha dos espaços, tamanhos, novas soluçóes técnicas, formas de exposição e colaboraçôes com outros artistas e outras disciplinas, mas sempre mantendo a mesma linha de pesquisa em que o inflável, mono-membrana, se relaciona com a arquitetura e reinterpreta o espaço.

El material constructivo estructural más econômico, de menos peso, más baja densidad, que existe abundantemente en cualquier lugar de la tierra y cuyo coste económico, hoy por hoy, es nulo y se puede adquirir sin necesidad de instancias o de permisos o crear problemas de propiedad, es el aire ¿Por qué no construir con aire?2 (POLE, 1974)

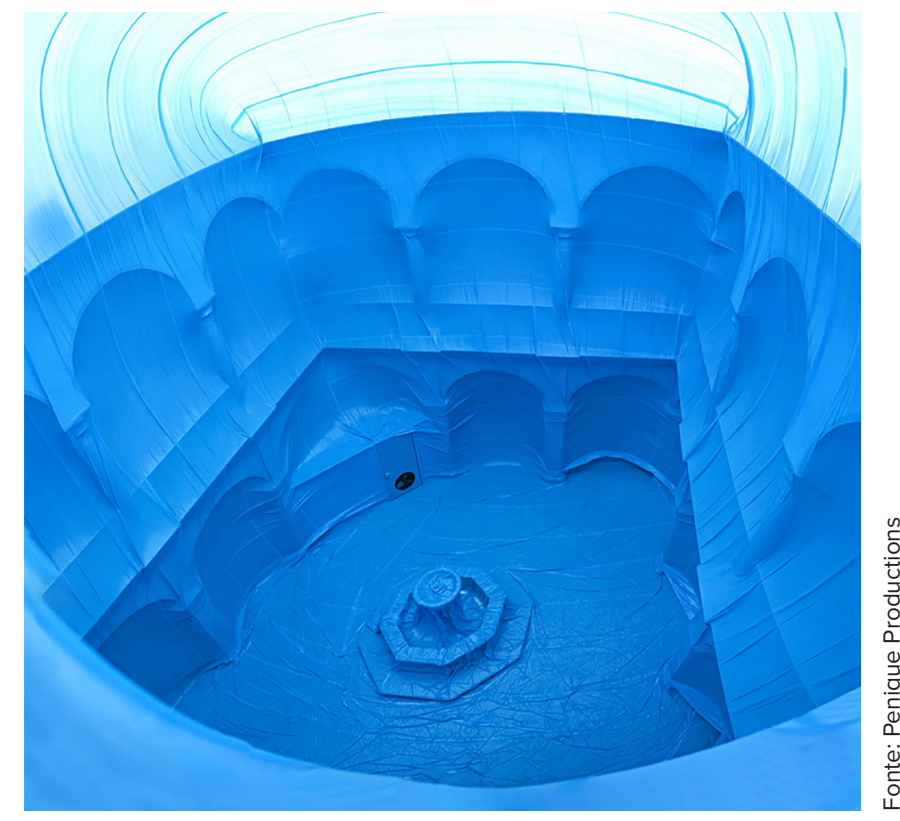

1. Inflável mono-membrana

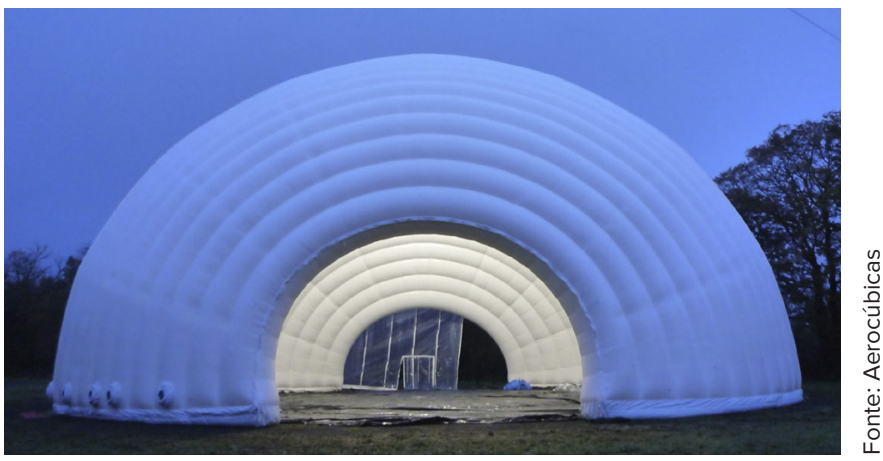

2. Inflável bi-membrana

No campo da "arquitetura inflável”, escultura inflável, penetráveis infláveis, instalações infláveis ou infláveis habitáveis, é possível distinguir dois grandes grupos: mono-membrana e bi-membrana. Os infláveis mono-membrana se diferenciam dos infláveis bi-membrana na medida em que os primeiros são feitos de uma camada só, em que o espaço habitável é o mesmo espaço que contém o ar à pressão. Os segundos são compostos de duas camadas, na sua 
totalidade ou em parte, e o espaço habitável não é o espaço onde o ar submetido à pressão atua de forma estrutural. Nesta condição, os infláveis bi-membrana costumam trabalhar com pressões mais elevadas e maior estanqueidade, conseguindo erguer estruturas sólidas como colunas, lajes, arcos, muito mais habituais na arquitetura sólida, tradicional.

No caso de Penique Productions, o conceito de mono-membrana foi o escolhido para criar obras que interajam com o entorno, a arquitetura, o espaço coletivo e as paisagens existentes, operando como intervençôes site-specific. O importante requisito para a realização desse tipo de intervenção, segundo Büttner (2002, p. 76), é a participação do artista no processo de planejamento do evento, de forma a interferir no contexto real e efetivo, estando a confrontação com o entorno colocada em primeiro plano. Assim, o ponto de partida de cada projeto do Penique Productions é a seleção de um local para a construção de uma peça única de tamanho específico, um inflável que se expanda e invada o espaço completamente. Nessas obras, o balão de ar cresce para interagir com a arquitetura existente. $\mathrm{O}$ ar, atuando de forma estrutural, faz pressão contra o plástico, que adere às superfícies e objetos que o limitam e, assim, modelam a forma final. Conquistado pelo inflável, o espaço se transforma através da nova textura, iluminação e monocromia. Desta forma, o espaço original perde seu uso habitual para se tornar parte da obra, assumindo uma nova identidade. O inflável funciona como fronteira e enquadra um novo espaço. $\mathrm{O}$ conteúdo é também o contentor, questionando a ideia de objeto artístico e oferencendo uma experiência ao espectador, que passa de observador a habitante.
Desde o princípio, o material usado para realizar as esculturas é o polietileno de baixa densidade (LDPE), "costurado" com fita adesiva. O uso destes materiais ordinários, de fácil aquisição, permite a autoprodução dos infláveis com certa agilidade e flexibilidade, permitindo fazer modificaçôes ao longo do processo e obter resultados relativamente portentosos com pouco orçamento.

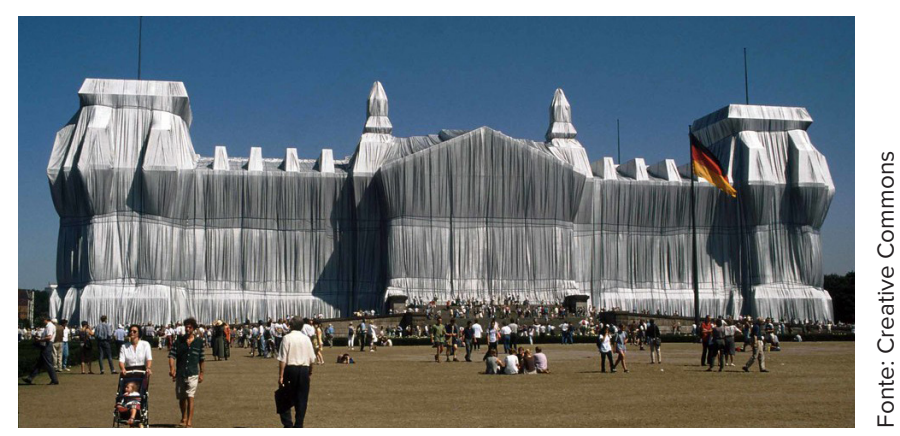

3. Christo and Jeanne-Claude, Wrapped Reichstag, 1995

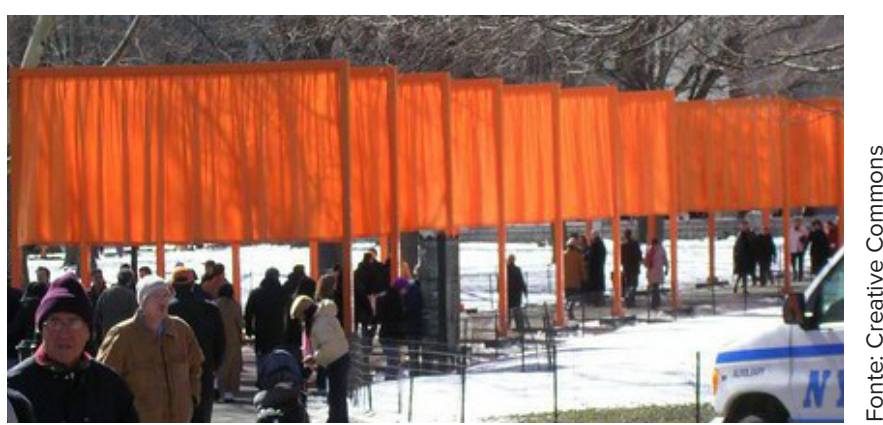

4. Christo and Jeanne-Claude, The Gates, 2005

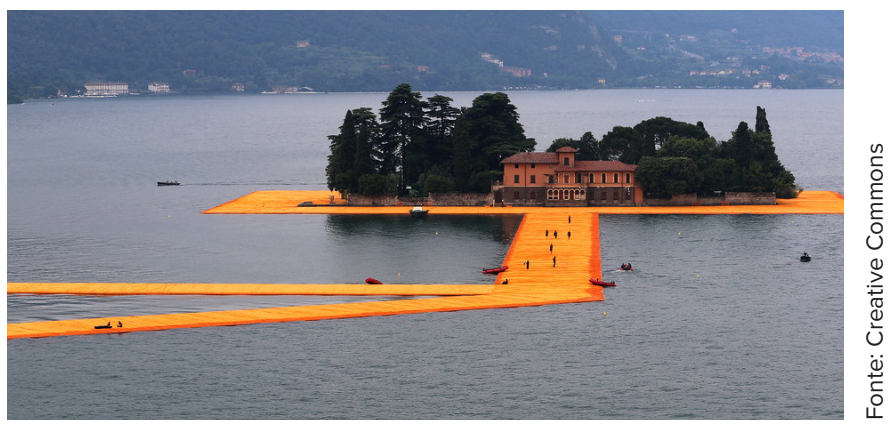

5. Christo and Jeanne-Claude, The Floating Piers, 2016 
As referências do Penique Productions residem em artistas contemporâneos como Christo \& Jeanne-Claude, nascidas na ocasião de uma visita destes à Faculdade de Belas Artes da Universitat de Barcelona, em 2006. A obra destes artistas tem como denominador comum o uso de tecidos, materiais frágeis, sensuais e leves que traduzem o caráter temporário das obras de arte ${ }^{3}$, que quase sempre se relacionam com a paisagem, o entorno, a cidade, e são obras de arte de grande porte.

Em um discurso mais abrangente e com uma certa perspectiva, podemos estabelecer também relaçóes entre a obra do coletivo Penique Productions e a produção de artistas como: Hans Hemmert, pelas ex-

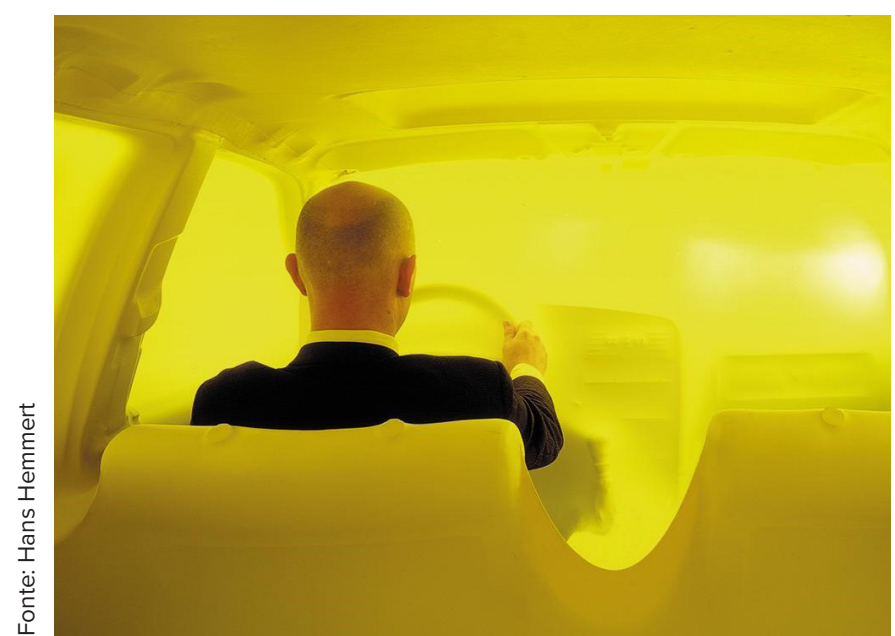

6. Hans Hemmert, Unterwegs, 1996

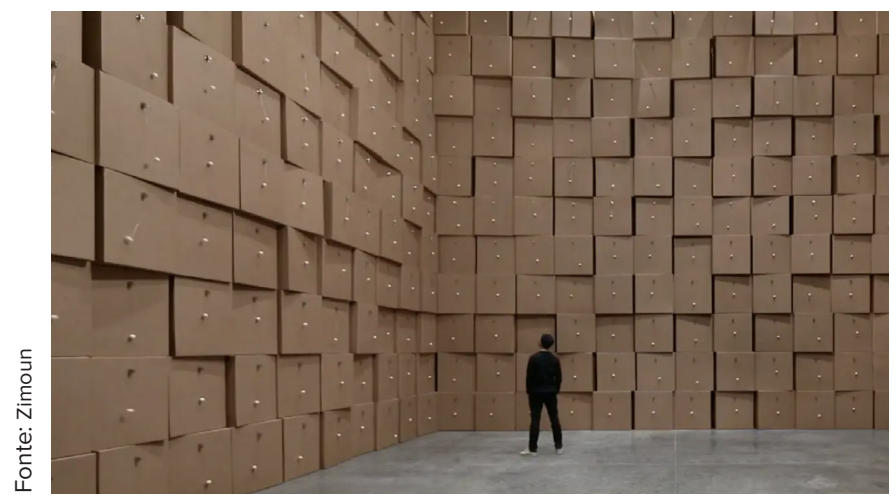

7. Zimoun, 658 prepared dc-motors, cotton balls, cardboard boxes, 2017

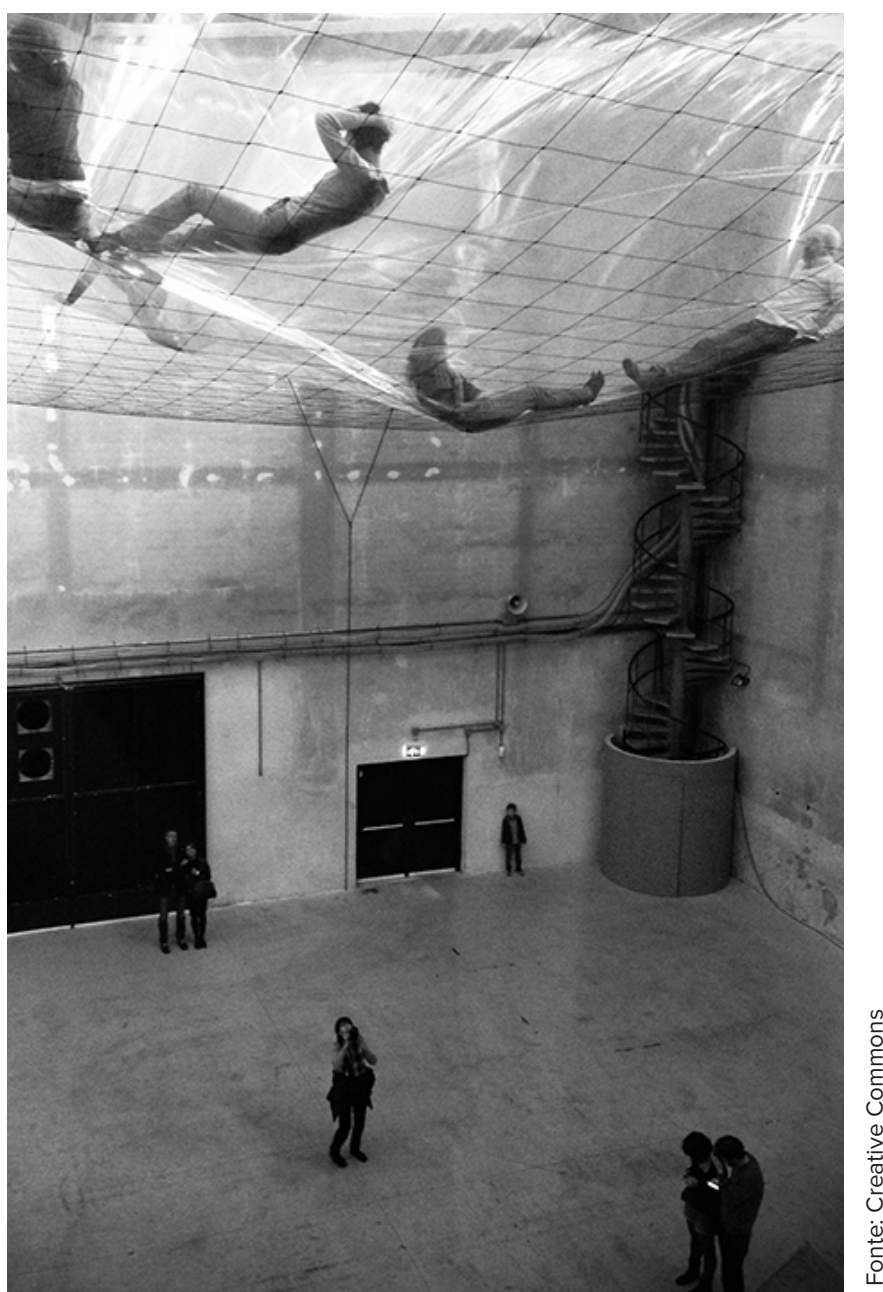

8. Tomás Saraceno, On Space Time Foam, 2012

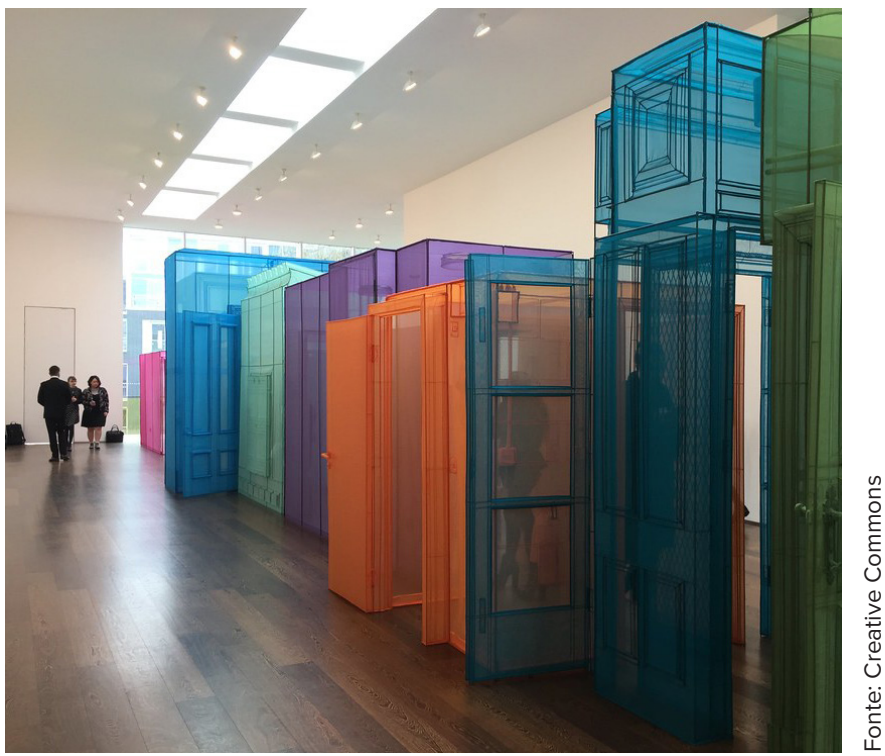

9. Do Ho Suh, Passage/s, 2017

Revista online do Departamento de Arquitetura e Urbanismo da Pontifícia Universidade Católica -

Puc-Rio - Rio de Janeiro Brasil

Ano $4-N^{\circ} 7$ - ISSN 2446-7340 


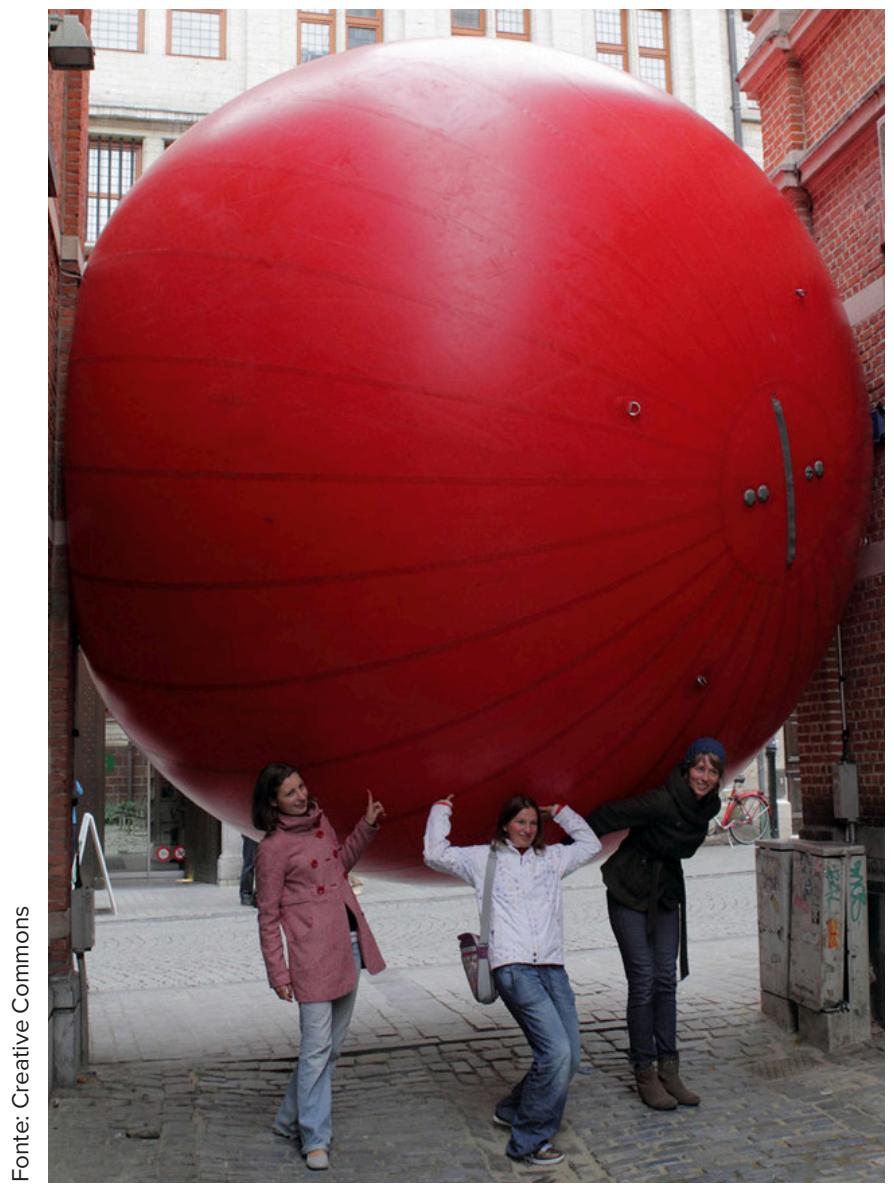

10. Kurt Perschke, Red Ball Project

periências realizadas com infláveis relacionados com objetos; Tomás Saraceno, pela pesquisa realizada no uso do ar como estrutura e o caráter lúdico e experimental da obra; Kurt Perschke (Red Ball Project), pela relação com a paisagem e a arquitetura; Do $\mathrm{Hu}$ Suh, pela leveza, escala, relaçáo com a arquitetura e transitabilidade; Henrique Oliveira, pelas formas; Zimoun, pelos materiais e o discurso simples e aberto; e o coletivo artístico Ant Farm, em seus primeiros trabalhos, pelo processo e o método quando experimentaram com infláveis.

Penique Productions, no intuito de fazer o público participar da montagem da obra como ação artística e experiência estética, assim como repensar, em

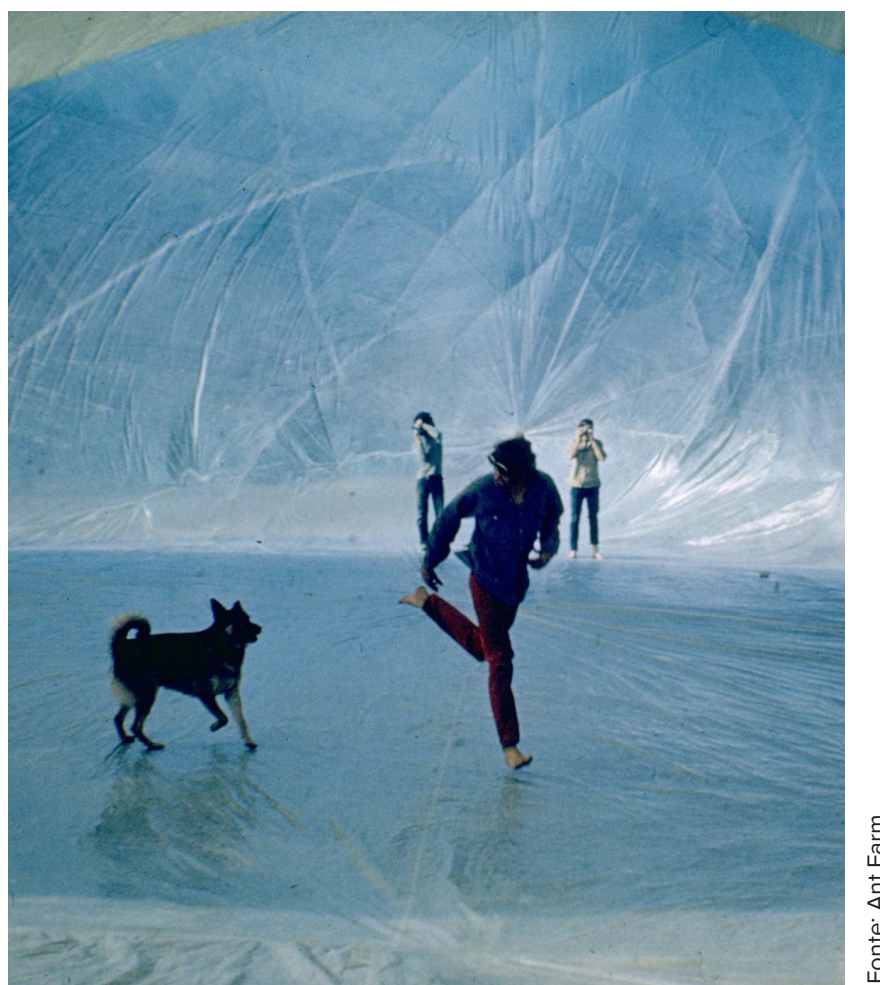

11. Ant Farm, Big Pillow, 1969

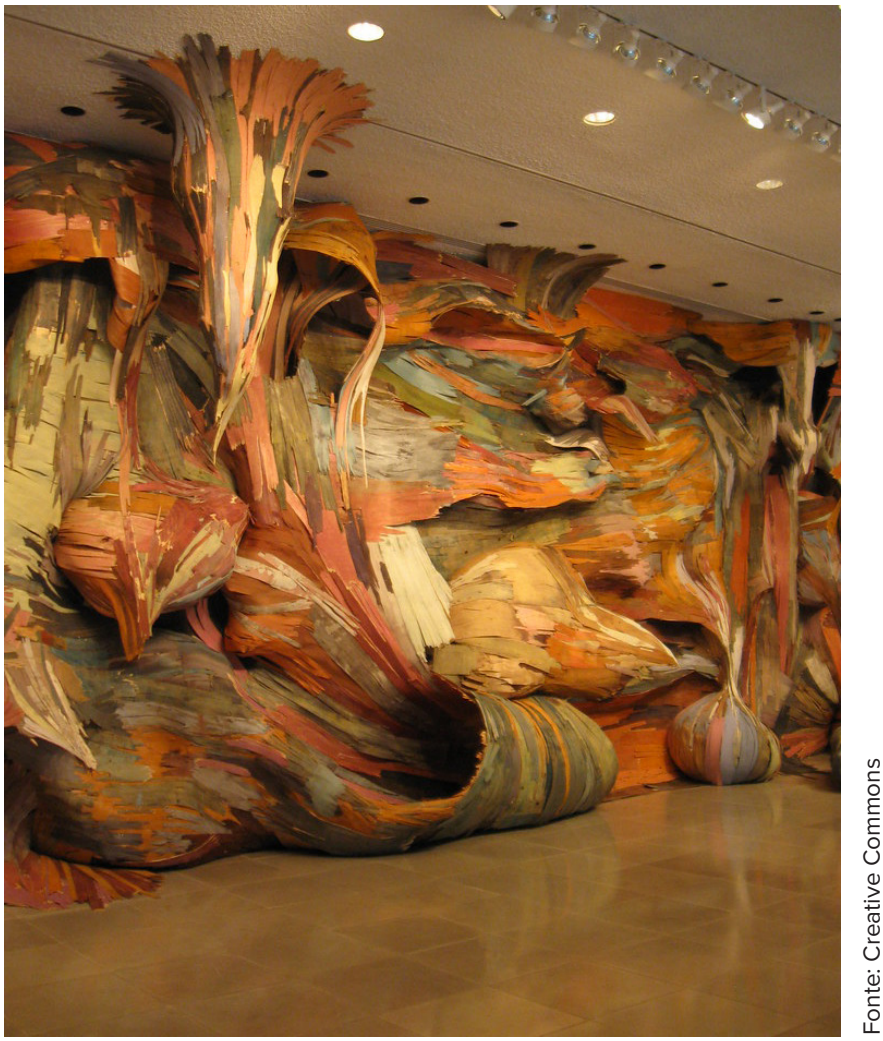

12. Henrique Oliveira, Tapumes, 2009

Revista online do Departamento de Arquitetura e Urbanismo da Pontifícia Universidade Católica -

Puc-Rio - Rio de Janeiro Brasil

Ano $4-N^{\circ} 7$ - ISSN 2446-7340 
conjunto, o fazer artístico e técnico, encontra no workshop um formato que permitiu um espaço de troca e aprendizado.

No ano de 2018, foram realizadas duas oficinas com estudantes para construção de infláveis em espaços coletivos. A primeira delas, chamada "Espaços efêmeros, construçóes leves", foi realizada na PUC-Rio, a partir de um curso de extensão aberto à comunidade externa, e a segunda, chamada "Inflável na Biblioteca da FAU”, foi realizada na FAU/UFRJ, a partir de uma atividade restrita aos estudantes da casa.

Ambas oficinas tiveram como objetivo construir uma obra que se relacionasse com os espaços coletivos dos dois campi. Na primeira, a opçáo do local ficou livre, cabendo às equipes escolher o sítio de sua proposta dentro do parque público da PUC, ao qual a cidade tem acesso. $\mathrm{Na}$ segunda oficina, o sítio da intervenção já estava dado, tratando-se do espaço desativado da antiga Biblioteca Lucio Costa, da FAU/UFRJ, localizada no mezanino do Edifício Jorge Machado Moreira, um lugar de acesso público.

\section{As oficinas - pensar, construir e experimentar}

O workshop "Espaços efêmeros, construçóes leves", realizado na PUC-Rio, teve como primeiro objetivo vivenciar a metodologia de Penique Productions. Normalmente, para as alunas e alunos de arquitetura, um processo de criação projetual é algo muito presente durante a formaçáo. No entanto, a possibilidade de experimentar um processo projetual e construtivo em verdadeira grandeza é algo pouco habitual, considerando que ele precisa da coordenaçáo de uma série de aspectos, entre os quais podemos mencionar a necessidade de um local para a execução e outro para localização da intervenção; a compra e transporte de materiais; soluçóes técnicas; mão de obra;

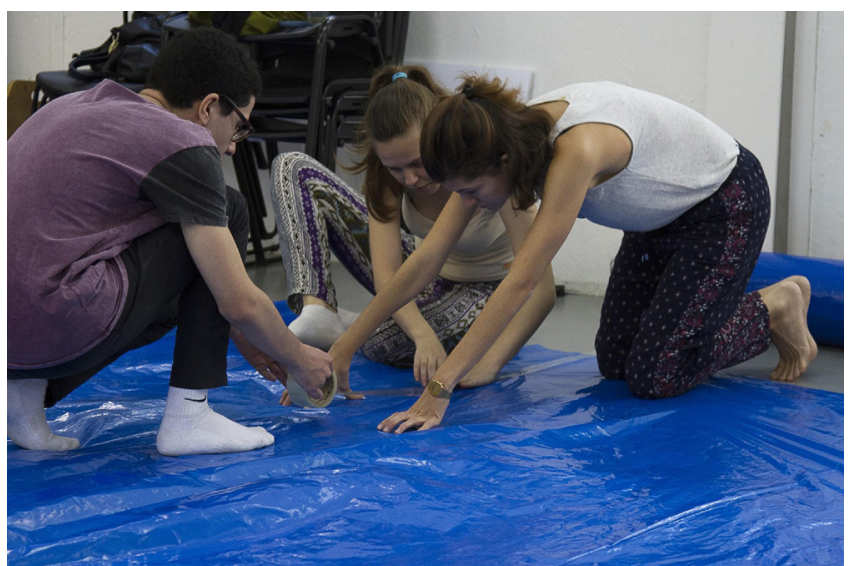

13. Fabricando o inflável do Grupo Azul, 2018

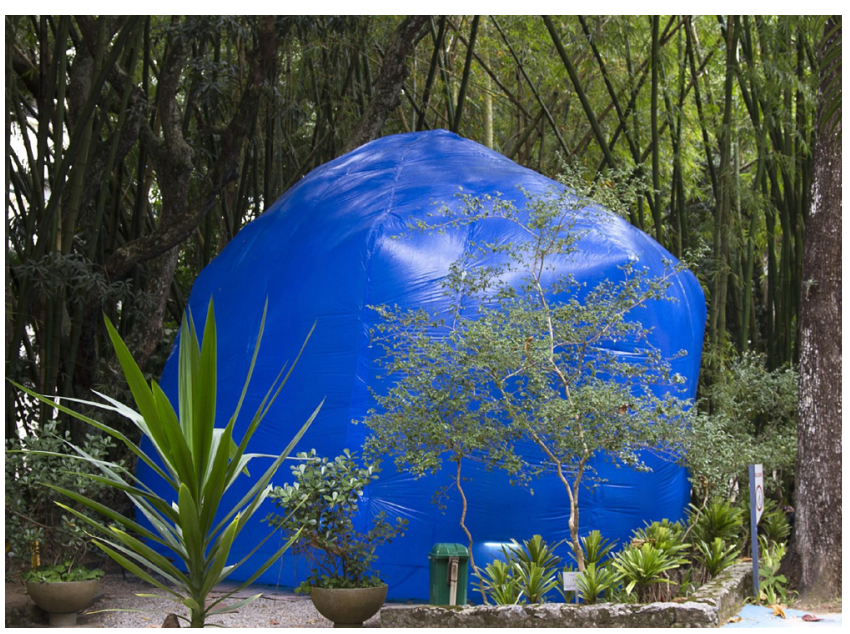

14. Instalação do Grupo Azul, 2018

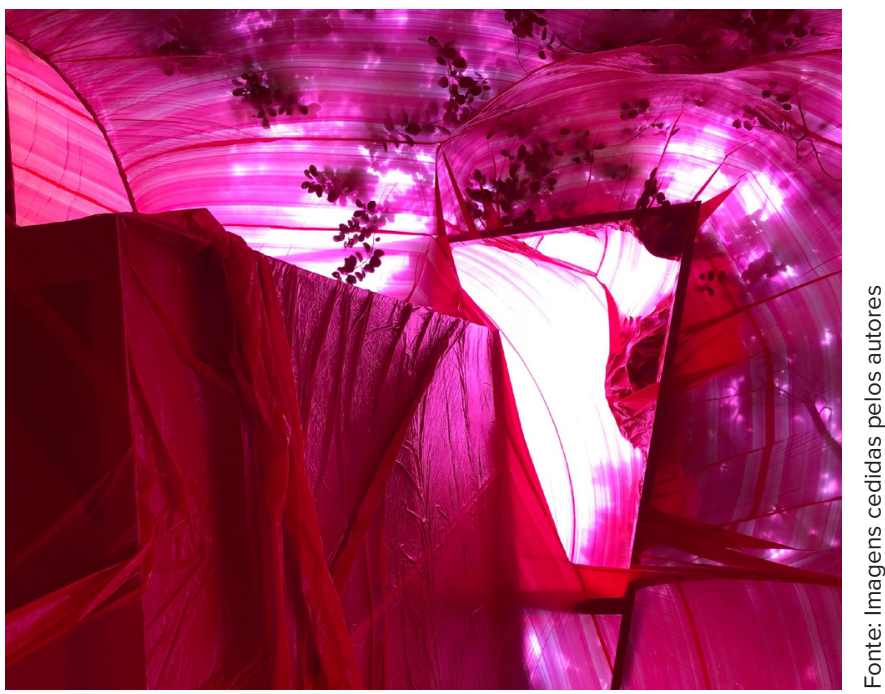

15. Interior da Instalação do Grupo Vermelho, 2018 


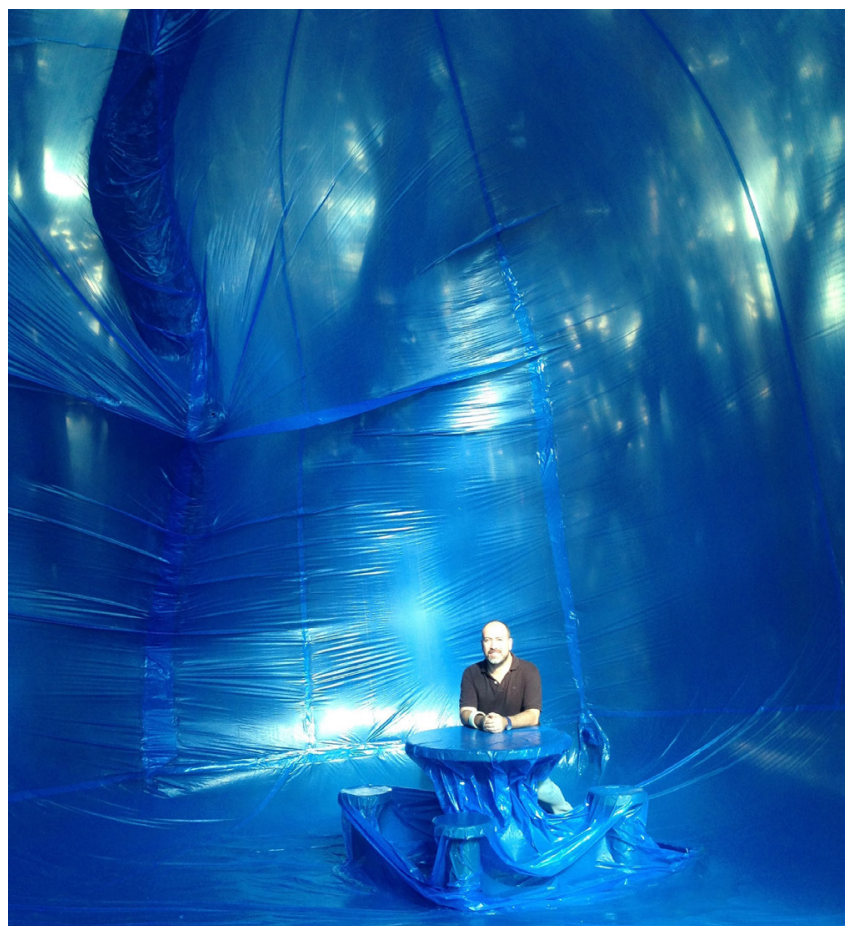

16. Fernando, no interior do Globo Azul, 2018

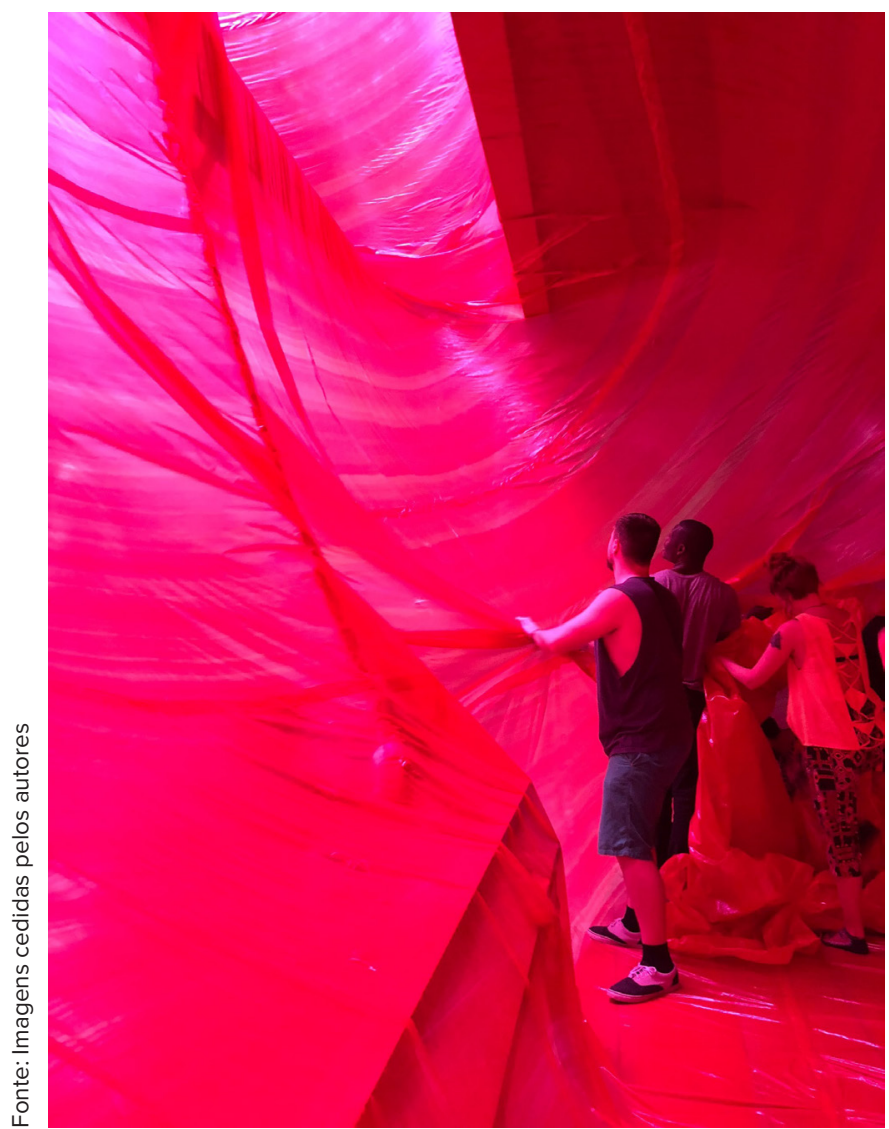

17. Instalando a Obra do Grupo Vermelho, 2018

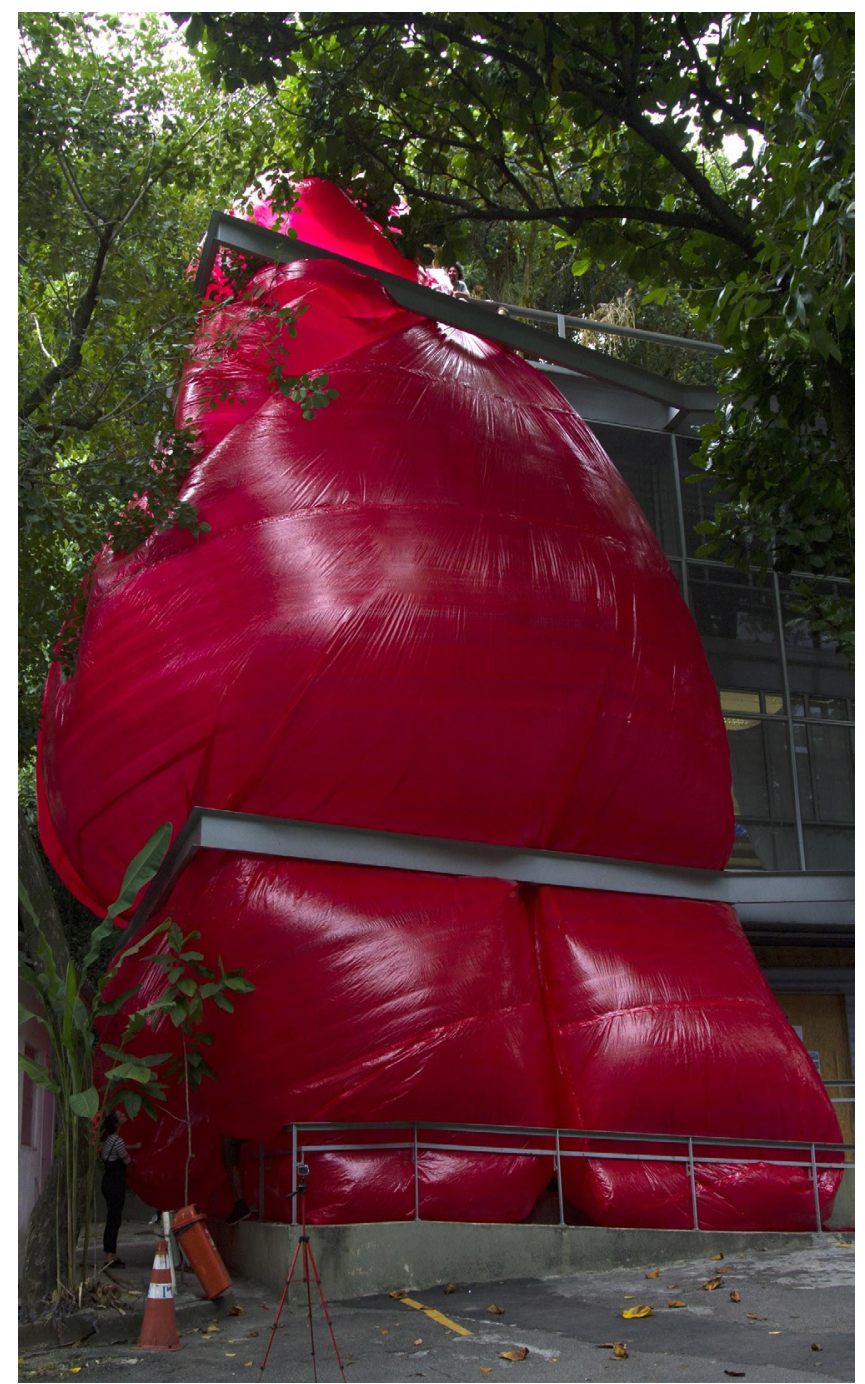

18. Instalação do Grupo Vermelho, 2018

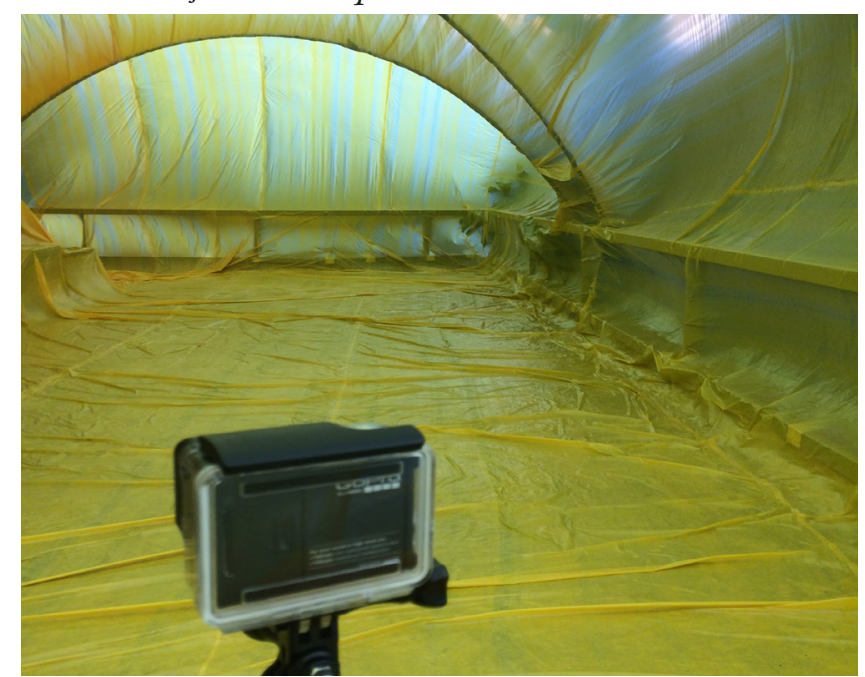

19. Interior da Instalação do Grupo Amarelo, 2018

Revista online do Departamento de Arquitetura e Urbanismo da Pontifícia Universidade Católica -

Puc-Rio - Rio de Janeiro Brasil

Ano $4-N^{\circ} 7$ - ISSN 2446-7340 
tempo. Trabalhar com infláveis, pelas suas características de leveza e construtibilidade, surge como uma oportunidade de articular, numa experiência só, as fases de projetar, construir e habitar. Por outro lado, oferece a oportunidade de vivenciar esse processo por meio de uma experiência estética de reinterpretação dos lugares escolhidos para as intervençôes. Assim, a arte se relaciona com o pensar arquitetônico por meio de uma interferência dos lugares cotidianos e dos usos habituais, neste caso, no parque e edificaçôes da PUC-Rio.

Durante 6 dias de trabalho (2 dias para a escolha dos lugares e idealização das intervençôes e 4 dias para a execução), os estudantes fundamentaram, projetaram e construíram 3 infláveis. O primeiro (amarelo) no terraço do edifício IMA; o segundo (vermelho) na fachada do mesmo edifício, invadindo parte do térreo; e o terceiro (azul) inserido na vegetaçáo do parque. No dia da ativação dos infláveis, a chuva trouxe uma inesperada variável, a água e o vento dificultando a estabilidade das intervençôes, mas também interagindo com as mesmas, que só se mantiveram infladas por algumas horas por motivos de estabilidade estrutural e segurança. A presença destes objetos coloridos de grande porte interferindo na paisagem impressionou. Porém, o estranhamento provocado nas percepçóes uma vez dentro da mesmas foi maior. A ambiência provocada pelo inflável interagindo com a arquitetura existente e a natureza, quase fagocitando-a, estimulou diversas interpretaçôes sobre lugares já conhecidos. A experiência de estar num lugar com dentro e fora num mesmo espaço trouxe a ideia de uma interface entre a arquitetura e seu entorno que poucas vezes exploramos e dos quais nem sempre estamos cientes.
A oficina Inflável na Biblioteca da FAU teve a participaçáo de 50 estudantes, reunidos para a construção de uma intervenção efêmera coletiva no espaço que abrigou a Biblioteca Lúcio Costa, no mezanino da Faculdade. O espaço sofre uma degradação paulatina desde 2016, processo que vem negligenciando sua potência arquitetônica. A intervenção surge para provocar a reflexão sobre a ressignificaçáo e re-ocupaçáo desse lugar tâo caro à comunidade da FAU-UFRJ.

A oficina teve a duraçáo de 3 dias, dedicados à fabricação, montagem e inflagem da obra. Em uma dinâmica de grupo, na forma de brainstorming, os estudantes intitularam a intervenção como "Ex.Vazio", em referência ao vazio simbólico preenchido de ar e ressignificado pela instalação monocromática. No dia da ativação da obra, conforme o Ex.Vazio se preenchia de ar, os participantes realizavam ajustes, como a construçáo dos pilares e a distribuição uniforme do plástico nas superfícies. Após o espaço estar bastante inflado, foi aberta uma porta para acesso. A visitação pública ocorreu entre os dias 3 e 5 de setembro de 2018.

Durante as visitações, o Ex.Vazio virou um palco das mais diversas apropriaçóes, provocando reflexóes e sensações nas pessoas que participaram da ação. O que "apareceu" como lugar deslocou as leituras cotidianas daquele espaço branco e vazio, alterando proporçóes, visadas e percepçóes. Entre as açóes de ocupação, destaca-se o evento de aniversário de 73 anos da FAU, quando a Companhia de Dança Contemporânea da UFRJ realizou uma performance. Mais de 1300 pessoas registraram sua passagem no livro de visitação, e mais de 400 participantes deixaram relatos sobre suas impressôes em relação ao espaço proposto. 


\section{ARTIGO \\ PRUMO}

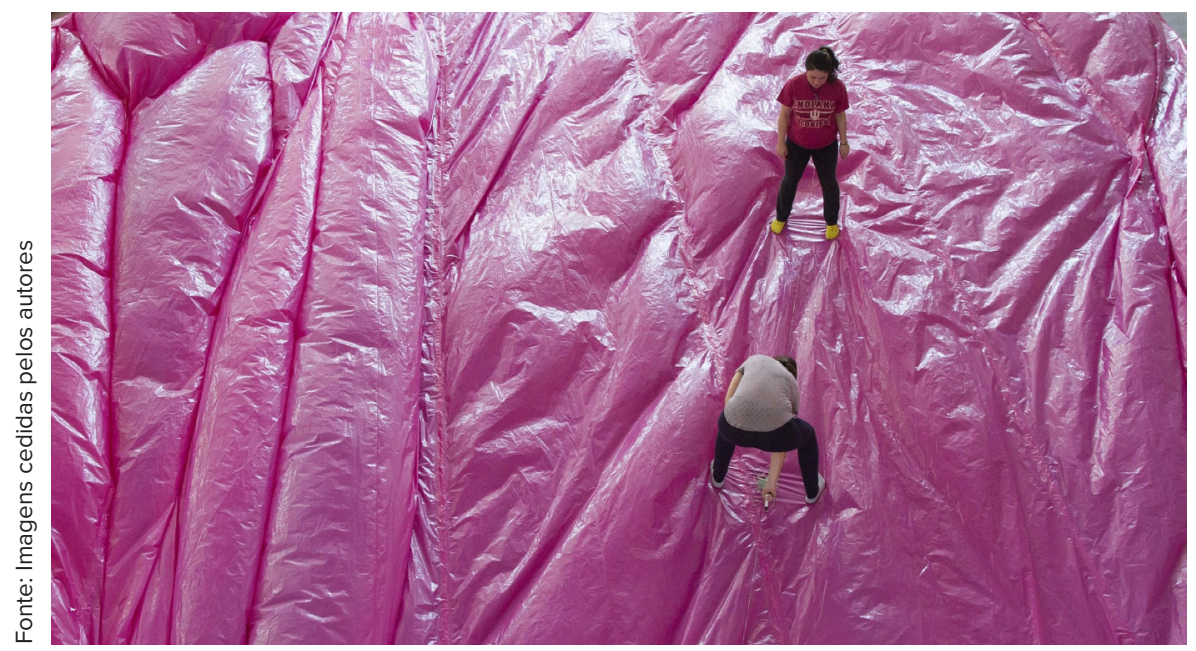

20. Fabricando Ex.Vazio, 2018

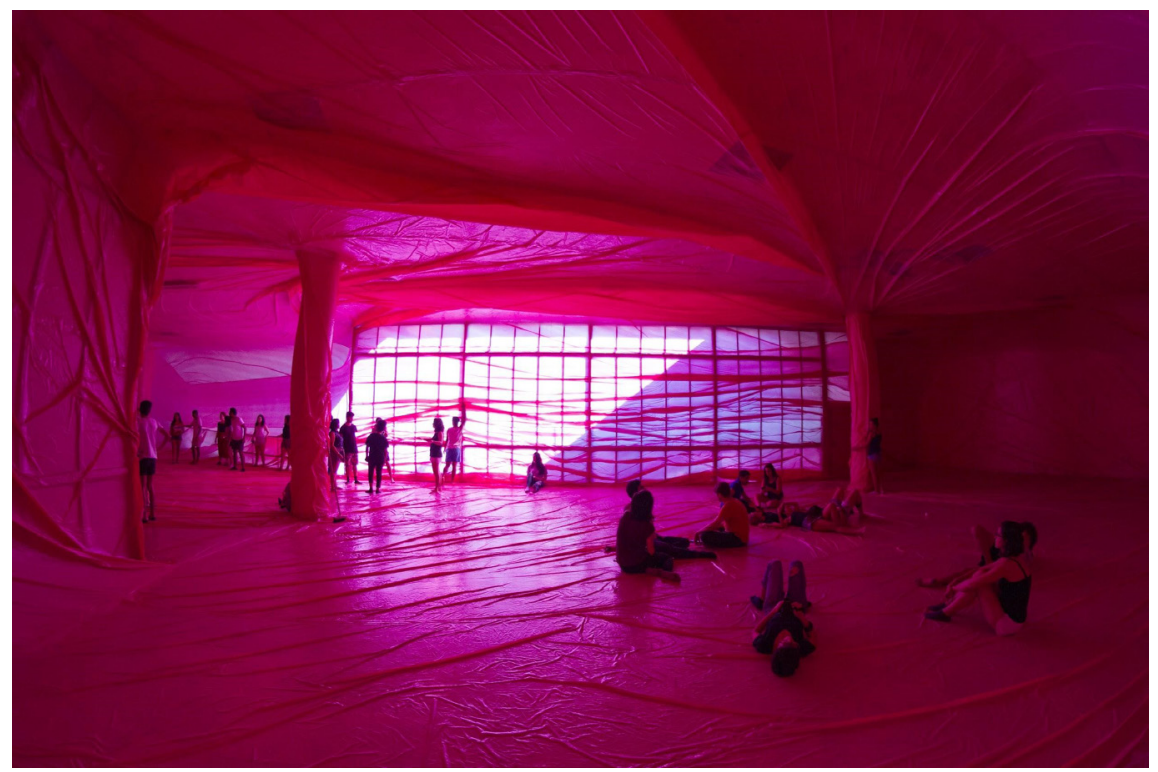

21. Ex.Vazio, 2018

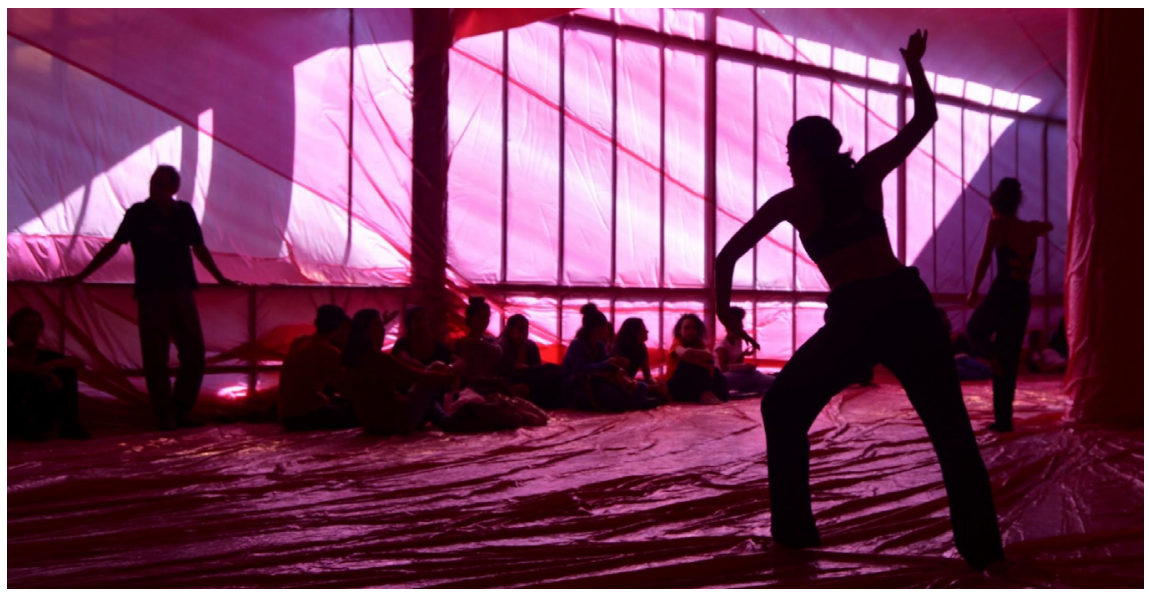

22. Dança contemporânea no Ex.Vazio, 2018

Revista online do Departamento de Arquitetura e Urbanismo da Pontifícia Universidade Católica -

Puc-Rio - Rio de Janeiro Brasil

Ano $4-N^{\circ} 7$ - ISSN 2446-7340 
Os visitantes usufruíram do espaço das mais diversas formas: lanchando, lendo, tirando fotos, pintando e desenhando. Aulas foram ministradas em seu interior e o inflável fez parte do dia a dia dos estudantes e demais pessoas que aproveitaram a presença efêmera dessa arte pública no edifício.

\section{Intervençáo efêmera e projeto site-specific}

Retomando a contribuição de Thibaud (2012) de que a noção de ambiência permite caracterizar nossas formas de experienciar a vida urbana, além de auxiliar na imaginação e criação de espaços urbanos e arquitetônicos, e considerando a efemeridade das obras apresentadas, tanto as referenciais, quanto as desenvolvidas pelos estudantes, é possível reconhecer as intervençôes efêmeras de arte pública como açóes estéticas cuja particularidade é sair dos espaços institucionais para tomar o espaço urbano, buscando novas formas de interação com o usuário. Normalmente executadas por meio de iniciativas singulares de artistas ou de coletivos de arte, valorizam a criação e sua representação espacial no ambiente urbano cotidiano. Apesar da rápida duração, uma vez voltadas à interferência direta com a vida cotidiana podem motivar também certas transformaçôes mais duradouras (Sansão-Fontes, 2013). Assim, e lembrando as palavras de Bajtin, a arte e a vida são realmente capazes de se relacionar por meio desse vínculo externo que, neste caso, estimula e provoca novas interpretaçóes do espaço habitado.

O objetivo desse tipo de ação é a ativação dos espectadores passivos, transformando-os em usuários ativos dos espaços urbanos, colocando em pauta uma reflexão sobre questôes cotidianas e buscando novas formas de comunicação no espaço coletivo, que não as pautadas pela indiferença.
Por sua capacidade de reagir diante de novas circunstâncias, a arte, segundo Büttner (2002), pode exercer importante papel no cotidiano. Para dotar a arte de uma funçáo pública, por um lado, o artista deve ter como princípio indispensável criar obras artísticas "com e para" determinado lugar, abusando do confronto com o contexto e descobrindo, destacando e valorizando temas e lugares. Para produzir seu efeito especial, por outro lado, a intervenção precisa lidar com o fator tempo, ou seja, ter uma existência passageira, e buscar a inclusão dos espectadores ou habitantes.

A disponibilização da cidade por meio da arte abre novas possibilidades de apropriação e usufruto dos espaços urbanos. Segundo Pallamin (2002, p. 108), a arte pública ressignifica o espaço, criando situaçôes inéditas de visibilidade, apontando ausências notáveis ou resistências às exclusôes no domínio público, desestabilizando expectativas e criando novas convivências. Sua potência está em desregular valores cristalizados e abrir novas extensôes do espaço vivido.

A paisagem contemporânea, vista menos como cena para contemplação e mais como campo mutável através do movimento e do tempo (Corner, 1999, p. 13), transforma-se em um lugar e um meio fértil para a expressão artística. Segundo Corner (1999), a paisagem não é dada, mas feita e refeita, é uma herança que deve ser recuperada, cultivada e projetada para novas re-existências. As intervençóes de arte pública tratadas aqui voltam-se ao encontro e embate da arte contemporânea com o público e o espaço, buscando a mudança do olhar em relação à cidade por meio de intervençôes em paisagens cotidianas. 


\section{Notas de fim:}

1. the fact of finding interesting or valuable things by chance. N.T.: o fato de encontrar coisas interessantes ou valiosas por acaso.

2. N.T.: O material construtivo estrutural mais econômico, de menor peso, menor densidade, que existe abundantemente em qualquer lugar da terra e cujo custo econômico, atualmente, é nulo e pode ser adquirido sem necessidade de instâncias ou autorizaçóes ou criar problemas de propriedade, é o ar. Por que não construir com ar?

3. Disponível em: https://christojeanneclaude.net/. Acessado em: 27 abril de 2019.

\section{Fonte das imagens}

1. PENIQUE PRODUCTIONS. El Claustro. Disponível em: <http://peniqueproductions.com/index.php/ project/el-claustro/>. Acesso em: 01 de maio de 2019.

2. ÀREACÚBICA. Grandes Cubiertas. Dísponível em: $<$ https://areacubica.com/grandes-cubiertas $>$. Acesso em: 01 de maio de 2019.

3. "Verhüllter/wrapped Reichstag" by motohakone is licensed under CC BY-NC-SA 2.0.

4. "DSCN1274" by adad is licensed under CC BY-NC-ND 2.0.

5. "The Floating Island" by simply lory is licensed under CC BY-NC-ND 2.0.

6. HEMMERT, Hans. Unterwegs. Disponível em: $<$ https://ingesidee.de/>. Acesso em: 27 de abril de 2019.

7. ZIMOUN. 658 prepared dc-motors, cotton balls, cardboard boxes. Disponível em: <https://www.zimoun. net/>. Acesso em: 27 de abril de 2019.

8. "RedBall Leuven - Kiekenstraat" by CarolienC is licensed under CC BY-NC-ND 2.0.

9. By acme london is licensed under CC BY-NC 2.0

10. "On Space Time Foam" by Daniele Pelligra is licensed under CC BY-NC-ND 4.0
11. ANT FARM. Big Pillow. In: SCOTT, Felicity D. Living Archive 7: ANT FARM. Barcelona: Actar D, 2008.

12. "Henrique Oliveira, "Tapumes"(Detail) @ Rice University Art Gallery 2" by Mr. Kimberly is licensed under CC BY-NC-SA 2.0

13. AUTORES. Fabricando o inflável do Grupo Azul. Rio de Janeiro, 2018.

14. . Instalação do Grupo Azul. Rio de Janeiro, 2018.

15. Interior da Instalação do Grupo Vermelho. Rio de Janeiro, 2018.

16. Fernando, no interior do Globo Azul. Rio de Janeiro, 2018.

17. Rio de Janeiro, 2018. Instalando a Obra do Grupo Vermelho.

18. neiro, 2018. . Instalação do Grupo Vermelho. Rio de Ja19. Rio de Janeiro, 2018. Interior da Instalação do Grupo Amarelo. 20. Fabricando Ex.Vazio, 2018. Rio de Janeiro, 2018.

21. Ex.Vazio, 2018. Rio de Janeiro, 2018.

22. de Janeiro, 2018. Dança contemporânea no Ex.Vazio. Rio

\section{Referências Bibliográficas}

ANT FARM. Inflatocookbook. 3 Edição. São Francisco, Kadist, 2018. Disponível em: <http://inflatocookbook. kadist.org/>. Acesso em: 27 de abril de 2019.

BAJTIN, M. Estética de la creación verbal. México DF: Editorial Siglo XXI, 1990, 400 p.

BÜTTNER, Claudia. Projetos artísticos nos espaços não-institucionais de hoje. In Pallamin, Vera M. (org). Cidade e Cultura: esfera pública e transformação urbana. São Paulo: Estação Liberdade, 2002.

CORNER, James (ed.). Recovering Landscape. Essays in 
Contemporary Landscape Architecture. Nova York: Princeton Architectural Press, 1999.

KANDINSKY, Vasilly. De lo espiritual en el arte. Barcelona: Editorial Paidos, 2002.

MÁSTER ARQUITECTURAS EFÍMERAS (Org.). Hinchables, La Galería: Arquitectura, arte y diseño español. Madrid: Conarquitectura ediciones, 2017, p. 8.

NORBERG-SCHULZ, Christian. Los principios de la arquitectura moderna. Barcelona: Editorial Reberté, 2005.

PALLAMIN, Vera. Arte urbana como prática crítica. In Pallamin, Vera M. (Org). Cidade e Cultura: esfera pública e transformação urbana. São Paulo: Estação Liberdade, 2002.

PALLASMAA, Juhani. Los ojos de la piel. Barcelona: Editorial Gustavo Gili, 2006.

PENIQUE PRODUCTIONS. Works. Barcelona, 2013. Disponível em: <http://www.peniqueproductions.com/>. Acesso em: 27 de abril de 2019.

SANSÃO FONTES, Adriana. Intervençōes temporárias, marcas permanentes. Apropriaçôes, arte e festa na cidade contemporânea. Rio de Janeiro: Casa da Palavra, 2013.

SCOTT, Felicity D. Living Archive 7: ANT FARM. Barcelona: Actar D, 2008.

THIBAUD, Jean-Paul. "La ville à l'épreuve des sens". In: Olivier Coutard \& Jean-Pierre Levy (eds.). Ecologies Urbaines. Paris: Editions Economica, 2010, p. 198-213. 